University of Wollongong

Research Online

Faculty of Engineering and Information

Faculty of Engineering and Information

Sciences - Papers: Part A

Sciences

$1-1-2015$

Treatment of shale gas drilling flowback fluids (SGDFs) by forward

osmosis: membrane fouling and mitigation

Gang Chen

Chinese Academy of Sciences

Zhongwei Wang

Chinese Academy of Sciences, zhongwei@uow.edu.au

Long D. Nghiem

University of Wollongong, longn@uow.edu.au

Xue-mei Li

Chinese Academy of Sciences

Ming Xie

University of Wollongong, mx504@uowmail.edu.au

See next page for additional authors

Follow this and additional works at: https://ro.uow.edu.au/eispapers

Part of the Engineering Commons, and the Science and Technology Studies Commons

Research Online is the open access institutional repository for the University of Wollongong. For further information contact the UOW Library: research-pubs@uow.edu.au 


\title{
Treatment of shale gas drilling flowback fluids (SGDFs) by forward osmosis: membrane fouling and mitigation
}

\author{
Abstract \\ A polyamide thin-film composite (TFC) forward osmosis (FO) membrane was fabricated and compared to \\ a commercially available cellulose acetate (CTA) membrane for treating shale gas drilling flow-back fluids \\ (SGDFs). The polyamide TFC membrane outperformed its CTA counterpart in terms of pure water flux and \\ reverse salt flux when synthetic brine was used as the feed. More severe fouling was observed for the \\ polyamide TFC membrane as compared to the CTA counterpart when treating SGDF. Very quick buildup of \\ fouling was identified for TFC membrane but not significant for CTA membrane. Ultrafiltration pre- \\ treatment delayed but did not alleviate fouling formation. Surface modification of the TFC membrane by \\ poly(ethylene gycol) (PEG) grafting resulted in reduced membrane fouling and marginal decrease in water \\ flux.

\section{Disciplines} \\ Engineering | Science and Technology Studies

\section{Publication Details} \\ Chen, G., Wang, Z., Nghiem, L. D., Li, X., Xie, M., Zhao, B., Zhang, M., Song, J. \& He, T. (2015). Treatment of \\ shale gas drilling flowback fluids (SGDFs) by forward osmosis: membrane fouling and mitigation. \\ Desalination, 366 113-120. Desalination

\section{Authors} \\ Gang Chen, Zhongwei Wang, Long D. Nghiem, Xue-mei Li, Ming Xie, Baolong Zhao, Mengxi Zhang, \\ Jianfeng Song, and Tao $\mathrm{He}$
}




\section{Treatment of Shale Gas Drilling Flowback Fluids (SGDF)} by Forward Osmosis: Membrane fouling and mitigation

4

\section{Gang Chen ${ }^{1}$, Zhouwei Wang ${ }^{1}$, Long D. Nghiem ${ }^{2}$, Xue-Mei Li ${ }^{1}{ }^{*}$, Ming Xie $^{2}$,} Baolong Zhao ${ }^{1}$, Mengxi Zhang ${ }^{1,3}$, Jianfeng Song ${ }^{1,3}$, Tao He ${ }^{1,4} *$

\author{
${ }^{1}$ Membrane Materials and Separation Technology, Shanghai Advanced Research \\ Institute, Chinese Academy of Sciences, Shanghai, China \\ ${ }^{2}$ Strategic Water Infrastructure Laboratory, School of Civil, Mining and \\ Environmental Engineering, University of Wollongong, Wollongong, NSW 2522, \\ Australia \\ ${ }^{3}$ University of Chinese Academy of Sciences, Beijing, 100049, China \\ ${ }^{4}$ School of Physical Science and Technology, ShanghaiTech University, Shanghai, \\ 201210, China \\ Corresponding authors: lixm@sari.ac.cn, het@sari.ac.cn \\ Tel: +86-21-20325162; Fax: 0086-21-20325034
}

Submitted to Desalination 
25 Abstract

A polyamide thin-film composite (TFC) forward osmosis (FO) membrane was

27 fabricated and compared to a commercially available cellulose acetate (CTA)

28 membrane for treating shale gas drilling flow-back fluids (SGDF). The polyamide

29 TFC membrane outperformed its CTA counterpart in terms of pure water flux and

30 reverse salt flux when synthetic brine was used as the feed. However, due to its rough

31 and hydrophobic surface, more severe fouling was observed for the polyamide TFC

32 membrane as compared to the CTA counterpart when SGDF (with a significant

33 foulant content) was used as the feed solution. Ultrafiltration pretreatment was not

34 effective to control fouling of the polyamide TFC membrane. On the other hand, the

35 results demonstrate that surface modification of the TFC membrane by poly (ethylene

36 gycol) (PEG) grafting could be used to control the membrane fouling. The PEGylated

37 TFC membrane prepared in this study showed similar fouling resistance as the

38 commercially available CTA membrane when real SGDF was used as the feed

39 solution.

40

41 Keywords: Shale gas; forward osmosis; high salinity water; membrane fouling;

42 PEGylation. 


\section{Introduction}

Hydraulic fracturing is a key technology in the exploration of shale gas, an important unconventional natural gas, which has been recognized as an essential component of the global energy mix to ensure supply continuity. During hydraulic fracturing, the fracturing fluid, consisting of mainly water mixed with sand and chemicals (such as surfactants, chelating agents, biocides), is injected at high pressure into the producing formation, creating fissures that allow natural gas to release from rock pores where it is trapped to the surface. About $70 \%$ of this fluid is returned to the surface after the fracturing process. It is commonly known as shale gas drilling flowback fluid (SGDF). In recent years, the treatment of SGDF has gained intensive research attentions because of its large volume, significant environmental impact, high salinity, and complicated composition [1-4]. Among several methods currently being explored, forward osmosis is possibly the most promising technology due to its resistance to fouling, process simplicity and high water recovery [5-9].

Forward osmosis is an osmotically driven membrane process, where the chemical potential gradient acts as the driving force for water transfer across the membrane from a dilute feed to a concentrated draw solution [5]. The treatment of drilling mud and flow-back water from shale gas exploration has been reported in several recent studies [2, 10-12]. Cellulose triacetate (CTA) FO membranes were used in most of these investigations [2, 12]. Despite the low fouling propensity of CTA FO membranes and their relatively low water flux, significant membrane fouling has been reported [2]. Polyamide FO membranes showed much higher flux and lower reverse 
salt diffusion than CTA counterparts. However, the fouling behavior has not yet been systematically investigated for treating real SGDF.

$$
\text { In this study, a thin-film composite (TFC) polyamide membrane was synthesized }
$$
to evaluate the treatment of SGDF in comparison to the commercially available CTA membrane. Synthetic brine and real SGDF with a similar ionic composition were used. The observation of fouling formation on the TFC FO membrane was reported in comparison to the CTA FO membrane. The effect of pretreatment using ultrafiltration for SGDF was investigated. The results also demonstrate that by PEGylating the TFC membrane surface, a more fouling resistant membrane could be obtained. This research provided important information on the attenuation of fouling during FO treatment of SGDF.

\section{Materials and methods}

\subsection{Chemicals and membrane materials}

Polysulfone (PSf, P3500) was purchased from Solvay. Flat sheet CTA membranes were obtained from Hydration Technology Innovations (Albany, OR). Sodium chloride $(\mathrm{NaCl})$ and potassium chloride $(\mathrm{KCl})$ were provided by Sinopharm Chemical Reagent Co., Ltd. M-phenylenediamine (MPD), triethyl amine (TEA), dimethyl sulfoxide (DMSO), trimesoyl chloride (TMC), and Jeffamine (ED 2003) were obtained from Sigma-Aldrich (Shanghai, China). Unless otherwise stated, all chemicals and solvents were of reagent grade. SGDF sample was supplied by a Chinese Petro company in Southwest China. The SGDF was filtered using GE 
Whatman Filter Paper $(40 \mu \mathrm{m})$ prior to any experiments and analyses to remove large solid particles. A synthetic solution having an ionic composition identical to that of the SGDF was prepared from analytical grade salts.

\subsection{Composition determination of SGDF}

Conductivity, $\mathrm{pH}$, and turbidity of the flow-back fluid were measured using a Mettler Toledo (LE703) conductivity meter, Sartorius pH meter (PB-10), Hach turbidity meter (2100Q), respectively. A Shimadzu Inductively Coupled Plasma Atomic Emission Spectroscopy (ICP AES, ICPE-9000) was used to determine the cation concentration of the flow-back fluid. Total hardness was determined using disodium ethylene diamine tetraacetate (EDTA-2Na) titration method. COD and $\mathrm{NH}_{3}-\mathrm{N}$ was determined by digestive degradation and measured by spectrophotometer (Hach DR2800) based on the standard methods. The distributions of the suspended particles were measured by dynamic light scattering (Malvern Zetasizer Nano ZS90). The top surfaces of both TFC and CTA membranes before and after experiments were analyzed by scanning electron microscopy equipped with energy dispersive X-ray spectroscopy (EDS) (Hitachi S-4800, Japan).

\subsection{Fabrication of TFC-FO membranes and surface modification}

\subsubsection{Support membrane preparation}

The support layer was prepared from PSf as follows: A mixture of PSf (18 g), PEG-400 (8 g), and DMAC (73.6 g) were stirred mechanically at $65{ }^{\circ} \mathrm{C}$ until a clear 
110

111 was filtered and then de-gassed. A film applicator (Elcometer 4340, Elcometer Asia

112 Pte. Ltd) was used to cast the membrane on a glass plate using a casting knife of 150

$113 \mu \mathrm{m}$. The glass plate was then immersed into a water bath at $30{ }^{\circ} \mathrm{C}$. The resulting PSf

114 membrane was washed and stored in DI water.

115

116

117

118

120

121

123

125

128

130

131

\subsubsection{Polyamide active layer fabrication}

To form the polyamide active layer, the top surface of the PSf membrane was brought into contact with a water phase, containing MPD (2 wt \%), DMSO (2 wt \%) and TEA (4 wt $\%$ ) for 2 min. The excess aqueous solution was decanted and the membrane surface was blown dry with nitrogen gas. The membrane was then brought into contact with a TMC hexane solution $(0.15 \mathrm{wt} . \%)$ for $1 \mathrm{~min}$ and dried in air for 2 min. Finally, the TFC polyamide membrane was cured in an oven at $100{ }^{\circ} \mathrm{C}$ for $3 \mathrm{~min}$, and stored in DI water before further experiments and analysis.

\subsubsection{PEGylation of the polyamide layer}

The TFC polyamide membrane surface was modified based on a PEGylation technique published procedure [13]. Briefly, after draining the excess TMC solution and before further curing step in an oven, the nascent polyamide layer was covered with Jeffamine solution (1.0 wt.\% in DI water) for $2 \mathrm{~min}$, resulting in reaction of the primary amine groups at the ends of the Jeffamine dangling acyl chloride groups on the polyamide surface. The modified membrane surface was dried in an oven at 100 
$132{ }^{\circ} \mathrm{C}$ for $3 \mathrm{~min}$. The obtained membranes were rinsed and stored in DI water before

133 further experiments and analysis.

134

$135 \quad 2.4$ Membrane testing systems and protocols

$136 \quad$ 2.4.1 Determination of membrane active layer properties

137 Key membrane transport parameters including pure water permeability

138 coefficient, $A$, salt permeability coefficient, $B$, and salt rejection, $R$, of the FO

139 membranes were determined using a laboratory-scale cross-flow reverse osmosis

140 system (Sterlitech Corporation) following the standard procedure previously

141 established by Cath et al [14]. The effective membrane area was $42 \mathrm{~cm}^{2}$. All

142 experiments were conducted at $25 \pm 1{ }^{\circ} \mathrm{C}$. The cross-flow velocity was maintained at

$1430.25 \mathrm{~m} / \mathrm{s}$. The intrinsic water permeability, $A$, was determined by:

$144 \quad A=J_{w} / \Delta P$

145 The pure water flux, $J_{w}$, was measured by dividing the volumetric permeate rate

146 by the membrane surface area with DI feed water under an applied trans-membrane

147 pressure of 10 bar. Salt rejection was characterized by keeping the applied pressure at

14810 bar and measuring the rejection of $1000 \mathrm{ppm} \mathrm{NaCl}$ solution with a calibrated

149 conductivity meter (Mettler Toledo LE703). The water flux using $\mathrm{NaCl}$ feed solution

150 is denoted as $J_{w}{ }^{N a C l}$. The observed $\mathrm{NaCl}$ rejection, $R$, was determined from the

151 difference between the bulk feed $\left(c_{b}\right)$ and permeate $\left(c_{p}\right)$ salt concentrations, $R=$

$1521-c_{p} / c_{b}$. The solute permeability, $B$, was determined from [15-17]: 
153 volume. The volume of both feed and draw solutions at the beginning of each 171 experimental run was 2.0 L. DI water and $0.5 \mathrm{M} \mathrm{NaCl}$ were used as the feed solution 172 and draw solution, respectively. The FO process was allowed to stabilize for $5 \mathrm{~min}$ 173 before each flux reading. The flux, $J_{v}$, was taken as the average reading over $30 \mathrm{~min}$

where $k$ represents the mass transfer coefficient for the cross-flow cell, and was calculated from correlation for a rectangular cell geometry and laminar flow [18].

\subsubsection{Structural properties determination}

A laboratory scale FO membrane system consisted of two half cells that could hold a flat sheet sample of $30 \mathrm{~cm}^{2}$ (i.e. length, width, and height were 10,3 , and 0.4 $\mathrm{cm}$, respectively). Two variable speed gear pumps (WT3000-1FA, Baoding Qili Precision Pump Co., Ltd) were used to circulate the feed and draw solutions concurrently. The feed and draw solution flow rates were monitored using rotameters. The temperature of the feed and draw solutions were maintained at $25 \pm 1{ }^{\circ} \mathrm{C}$. The weight of the feed and permeate reservoirs were determined by digital balances (CP4202C, OHAUS Corporation), which are connected to a computer for data logging. Membranes were tested under FO mode, where the feed water flows against the dense active layer. Both feed and draw solution flow velocity was maintained at $4.6 \mathrm{~cm} / \mathrm{s}$.

The FO water flux was measured by monitoring the change in the draw solution

$$
B=J_{w}{ }^{N a C l}\left(\frac{1-R}{R}\right) \exp \left(-\frac{J_{w}{ }^{N a C l}}{k}\right)
$$


174 by using the following equation:

175

$$
J_{v}=\frac{\Delta m}{A_{m} \times \Delta t \times \rho_{\text {draw }}}
$$

Where $\Delta m, \Delta t, A_{m}$, and $\rho_{\text {draw }}$ represent the mass of permeation water, time interval,

177 effective membrane surface area, and draw solution density, respectively. The change

178 of draw solution concentration was negligible and the ratio of water permeation to the

179 draw solution was less than $5 \%$.

180 The reverse salt flux, $J_{s}$, of the membrane was characterized by calculating the

181 change of salt content in the feed solution based on conductivity from the equation

182 (4):

183

$$
J_{S}=\frac{V_{t} C_{t}-V_{0} C_{0}}{A_{m} \Delta t}
$$

The solute resistivity, $K$, can be determined by the following equation [19]:

$$
K=\left(\frac{1}{J_{v}}\right) \ln \left(\frac{B+A \pi_{D, b}}{B+J_{v}+A \pi_{F, m}}\right)
$$
calculated according to Eq. 6,

$$
\frac{\pi_{F, m}}{\pi_{F, b}}=\exp \left(\frac{J_{v}}{k}\right)
$$

190 The membrane structural parameter, S, was defined as the product of the product

191 of $K$ and $D[20]$.

$$
S=K D
$$




\section{$212 \quad 3$ Results and discussion}

\subsection{Surface characterization} acquisition.

\subsubsection{Concentration of shale gas drilling flowback-fluid}

The FO concentration of SGDF or synthetic brine was carried out using the same laboratory-scale FO system as described above. Potassium chloride ( $\mathrm{KCl}, 3.0 \mathrm{M})$ was used as the draw solution [12]. Both feed and draw solutions (initial volume 2 L) were maintained at $30 \pm 1{ }^{\circ} \mathrm{C}$. The operation time varied from 12 to $48 \mathrm{~h}$ for different batch of experiments. The flux was calculated according to Eq. 3 but averaged at every 10 min. All settings were evaluated with at least one replicate to ensure experimental reproducibility. In this paper, only the representative profiles were included to demonstrate the membrane fouling tendency during FO process.

The membrane morphology was observed using scanning electron microscopy (SEM). Samples were prepared by cryogenic breaking, followed by drying under vacuum overnight at $30^{\circ} \mathrm{C}$ and gold coating. SEM images at low magnifications were taken by Hitachi TM-1000. For images of high magnifications, a field emission scanning electron microscopy (FESEM Hitachi S-4800) was utilized for image

\subsection{Characteristics of the FO membranes}

The TFC membranes were prepared by interfacial polymerization using TMC and MPD on a tailor-made PSf support. Fig. 1 shows both the top surface and 
cross-section of the TFC membrane fabricated in this study and the commercially

217 available CTA membrane. The TFC membrane has a rough polyamide surface with

218 myriads of corrugation (Fig. 1a). It is supported by a porous PSf layer but has no

219 mesh reinforcement (Fig 1b). The PSf supporting layer has finger-like voids in the

220 middle and sponge porous structure close to the both top and bottom surfaces. In

221 contrast, the commercially available CTA membrane has a smooth surface (Fig. 1c)

222 and is reinforced by an embedded mesh in the middle (Fig. 1d).
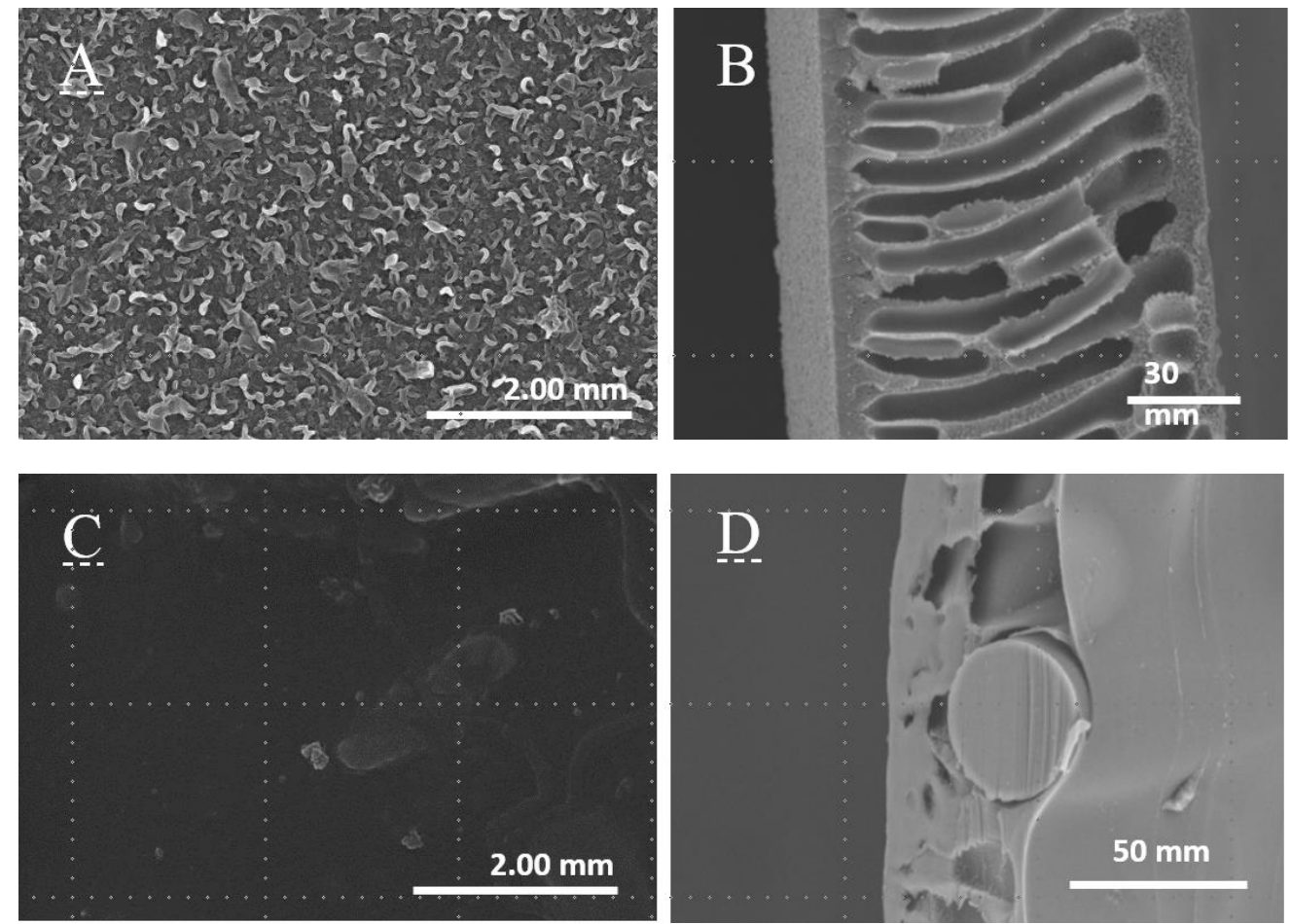

Figure 1: SEM images of the polyamide TFC membrane fabricated in this study

226 (A and B, the top surface and cross section, respectively) and the commercially

227 available CTA membrane (C and D, the top surface and cross section, respectively).

Key characteristics of the FO membranes are shown in Table 1. The TFC

230 membrane showed a pure water permeability, $A$, of $3.5 \mathrm{~L} / \mathrm{m}^{2} \mathrm{~h} \cdot$ bar, which is about 4 
231 times higher than that of the CTA membrane. However, when using the same draw

232 solution $(0.5 \mathrm{M} \mathrm{NaCl})$, water flux of the TFC membrane was about twice as high as

233 that of the CTA membrane. The difference in performance ratio between the A value

234 (water permeability) and the actual water flux in FO mode can be attributed to the

235 different structural parameters $(S)$ of these two membranes. The structural parameter

$236(S)$ of the TFC membrane $(519 \mu \mathrm{m})$ was considerably higher than that of the CTA

237 membrane $(421 \mu \mathrm{m})$. As a result, internal concentration polarization associated with

238 the TFC membrane is more severe than that associate with the CTA membrane.

239 The salt rejection of the TFC membranes in the RO test was also higher than that

240 of the CTA membrane. However, because the significantly higher water flux

241 compared to the CTA membrane, the solute permeability, $B$, of the TFC membrane is

242 slightly greater than that of CTA membrane. The ratio between the reverse solute flux

243 and FO water flux $\left(\mathrm{J}_{\mathrm{S}} / \mathrm{J}_{\mathrm{v}}\right)$ of the TFC membrane was $0.3 \mathrm{~g} / \mathrm{L}$, which is much smaller

244 than the CTA membrane $(1.17 \mathrm{~g} / \mathrm{L})$.

245

246 Table 1 Characteristics of tailor-made TFC FO membranes and commercial CTA

247 membranes

\begin{tabular}{|c|c|c|c|c|c|c|}
\hline Membrane & $\begin{array}{l}\text { Water Permeability } \\
\text { A }\left(\mathrm{L} / \mathrm{m}^{2} \cdot \mathrm{h} \cdot \mathrm{bar}\right)\end{array}$ & $\begin{array}{l}\text { Rejection } \\
(\%)\end{array}$ & $\begin{array}{l}\text { B value } \\
\left(10^{-7} \mathrm{~m} / \mathrm{s}\right)\end{array}$ & $\begin{array}{l}\text { S value } \\
(\mu \mathrm{m})\end{array}$ & $\begin{array}{l}\mathrm{J}_{\mathrm{v}} \\
\left(\mathrm{L} / \mathrm{m}^{2} \cdot \mathrm{h}\right)\end{array}$ & $\begin{array}{l}\mathrm{J}_{\mathrm{S}} / \mathrm{J}_{\mathrm{V}} \\
(\mathrm{g} / \mathrm{L})\end{array}$ \\
\hline TFC & 3.5 & 95 & 3.04 & 519 & 16 & 0.30 \\
\hline CTA & 0.79 & 89.1 & 2.39 & 421 & 8.7 & 1.17 \\
\hline
\end{tabular}


249 as feed under pressure of $10 \pm 0.1$ bar. $\mathrm{S}, \mathrm{Jv}$ and $\mathrm{J} / \mathrm{Jv}$ values were obtained from FO 250 test using $0.5 \mathrm{~mol} / \mathrm{L} \mathrm{NaCl}$ and deionized water as draw and feed solution respectively

251 under FO mode (active layer facing deionized water)

\subsection{Composition of SGDF}

253 The characteristics of the SGDF after pretreated with $40 \mu \mathrm{m}$ filter paper are 254 shown in Table 2. The SGDF used in this study was saline (conductivity of 11.29 $255 \mathrm{mS} / \mathrm{cm})$ and slightly alkaline $(\mathrm{pH}=8.2)$. The total dissolved solids (TDS) of the 256 SGDF was $6.9 \mathrm{~g} / \mathrm{L}$. Sodium and chloride were the dominant ions in this SGDF sample, 257 followed by potassium and calcium which were present at 393 and140 mg/L, 258 respectively. The concentrations of all other ions were insignificant. A synthetic brine 259 was prepared from deionized water and analytical grade salts to only include the 260 major ions found in the real SGDF (Table 2).

261 Table 2 Characterization of synthetic brine and SGDF pre-filtered by a qualitative 262 filter paper

\begin{tabular}{lcl}
\hline Analyzed items & SGDF & Synthetic brine \\
\hline Conductivity $(\mathrm{mS} / \mathrm{cm})$ & 11.29 & 11.3 \\
$\mathrm{pH}$ & 8.19 & -- \\
TDS (mg/L) & 6906 & -- \\
Turbidity (NTU) & 135 & -- \\
Calcium (mg/L) & 140.2 & 140 \\
Magnesium (mg/L) & 18.05 & 17.8 \\
Strontium (mg/L) & 4.9 & 4.9
\end{tabular}




\begin{tabular}{lll} 
Potassium $(\mathrm{mg} / \mathrm{L})$ & 393 & 393 \\
Sodium $(\mathrm{mg} / \mathrm{L})$ & 2109 & 2500 \\
Hardness $\left(\mathrm{CaCO}_{3} \mathrm{mg} / \mathrm{L}\right)$ & 283 & -- \\
$\mathrm{COD}_{\mathrm{Cr}}(\mathrm{mg} / \mathrm{L})$ & 358.5 & -- \\
Boron $(\mathrm{mg} / \mathrm{L})$ & 16.9 & -- \\
Sillicon $(\mathrm{mg} / \mathrm{L})$ & 19.2 & -- \\
NH & & - \\
Sulfate $(\mathrm{mg} / \mathrm{L})$ & 9.5 & -- \\
Carbonate $(\mathrm{mg} / \mathrm{L})$ & 2.2 & -- \\
Chloride $(\mathrm{mg} / \mathrm{L})$ & 149 & -- \\
\hline
\end{tabular}

$264 \quad 3.3$ FO concentration process

265 Major ionic components of the synthetic brine are of the same concentrations as 266 those in the real SGDF (Table 2). Thus, the synthetic brine and real SGDF are 267 expected to have similar osmotic pressure. In this study, the synthetic brine was used 268 as a reference (blank) since it contains no other contaminants except inorganic salt. 269 By controlling the FO concentration process to a state that the feed solution is far 270 from saturation, the fouling in FO process could be identified as the decline in the FO 271 flux against concentration ratio or time. The flux change with the concentration ratio 272 of feed was monitored using both CTA and TFC membranes as shown in Fig. 2.

273 When synthetic brine was used as the feed, the TFC membrane showed an initial 274 water flux nearly twice that of the CTA membrane (Fig. 2). The higher initial water 
275 flux of the TFC compared to the CTA membrane is consistent with the characteristics 276 of the FO membranes as reported in section 3.1. As the concentration ratio increased, 277 the synthetic brine was concentrated and the draw solution $(\mathrm{KCl})$ was diluted. As a 278 result, the water flux gradually decreased as the concentration ratio increased. 279 Interestingly, no obvious flux difference was observed using synthetic brine and real 280 SGDF in case of CTA membranes. However, the FO flux of TFC membrane for 281 synthetic water was significantly higher than that for SGDF.
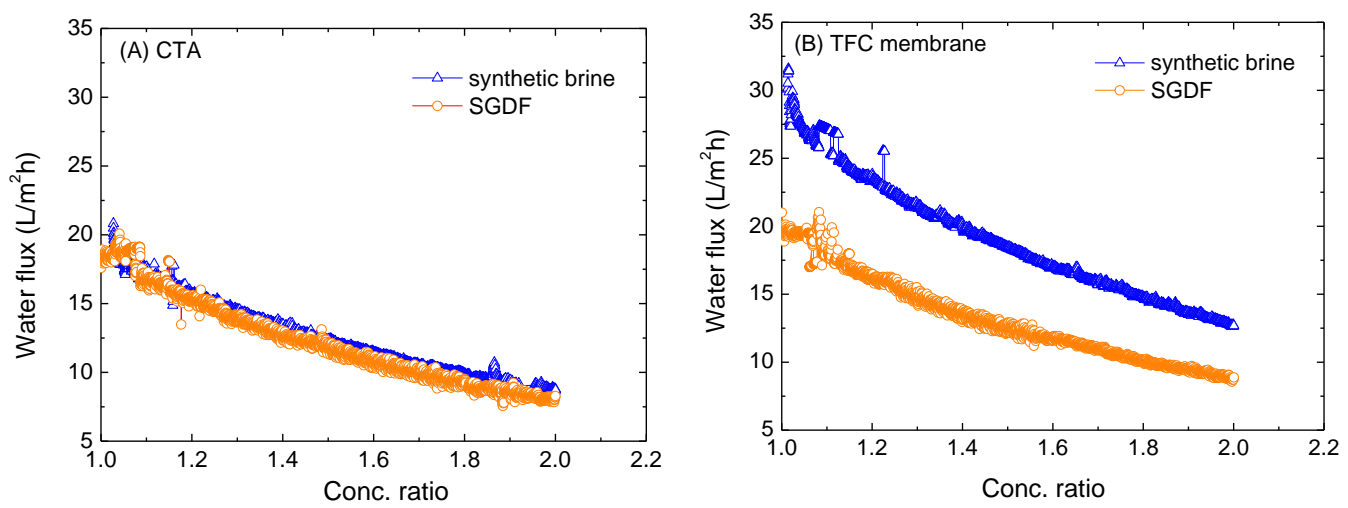

Fig. 2 Concentration of synthetic brine and real SGDF using both CTA and TFC

FO membranes (experiments were conducted continuously for 30 hours at cross flow velocity of $4.6 \mathrm{~cm} / \mathrm{s}$ using $3 \mathrm{~mol} / \mathrm{L} \mathrm{KCl}$ as the draw solutions. The feed and draw solution temperature was kept at $30^{\circ} \mathrm{C}$ ).

In order to give a better interpretation of results, we defined a water flux ratio, $289 \mathrm{~J}_{\mathrm{SG}} / \mathrm{J}_{\mathrm{SB}}$, and the values for both TFC and CTA membranes are shown in Fig. 3. In case 290 of the CTA membrane, $\mathrm{J}_{\mathrm{SG}} / \mathrm{J}_{\mathrm{SB}}$ was $\pm 95 \%$, much higher than that of the TFC 291 membrane of $75 \%$. The water flux ratio appears constant until the concentration ratio 292 reached around 2.0. It should be noted that at this point, the feed solution is far from 
saturation, thus no scaling is possible. The very high constant flux ratio for CTA

294 membrane indicates that no obvious fouling aggregation was built up on CTA

295 membrane during the FO process. The lower constant flux ratio for TFC membrane

296 shows that fouling occurred at the first beginning of the FO process and no further

297 fouling build-up was observed in the following FO process.

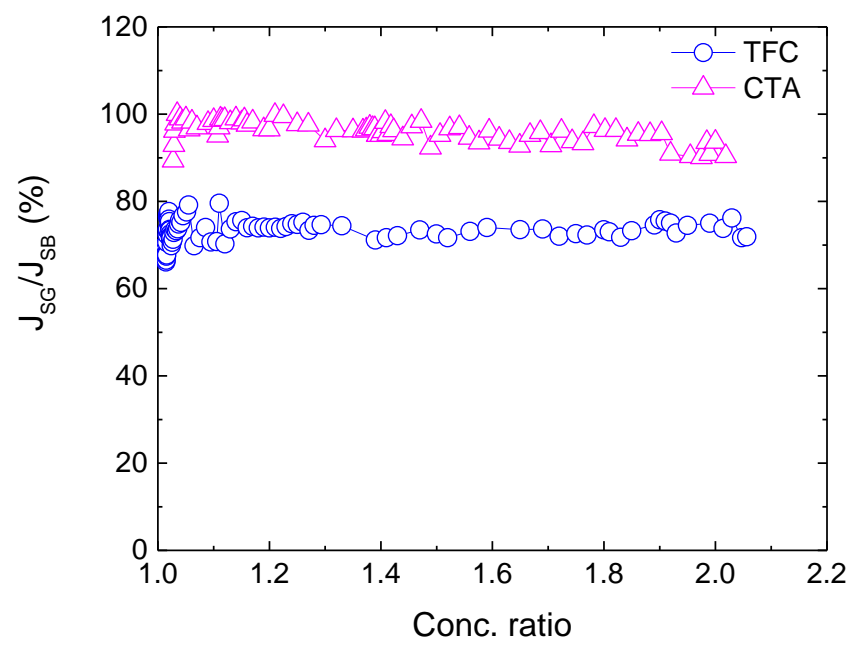

Fig. 3 Comparison of the FO water flux ratio for TFC and CTA membranes in

301 concentrating synthetic water and SGDF. $\mathrm{J}_{\mathrm{SG}}$ : FO water flux for SGDF; $\mathrm{J}_{\mathrm{SB}}$ : FO water 302 flux for synthetic brine.

305 SEM photos of the membrane surfaces for TFC and CTA membranes after treating 306 synthetic brine and SGDF. It is obvious that treating the synthetic brine, both top 307 surfaces of the TFC and CTA membrane remained clean. However, large crystals were 308 observed in the top surface of TFC membrane, and a few crystals were found in the 
top surface of the CTA membrane. The chemical compositions of the crystals were

310 analyzed with EDS as shown in Fig. 5. The EDS shows that the chemical

311 compositions for TFC membrane surface shows that the crystals contained $\mathrm{Ca}, \mathrm{Mg}, \mathrm{Sr}$

312 and $\mathrm{Cl}, \mathrm{C}$ and $\mathrm{O}$. It is most probable the precipitation of the $\mathrm{CaCO}_{3}, \mathrm{MgCO}_{3}$ and

$313 \mathrm{SrCO}_{3}$

314 Comparing the top surfaces of the TFC membrane after treating the synthetic

315 brine (Fig.4 A) and SGDF (Fig. 4 B), we noticed that the ridge-and-valley

316 morphology was not as clear as fresh membrane (Fig. 1A), neither as that after

317 treating synthetic brine. It appears that the initially rough surface was smeared by

318 other contaminants. This is probably correct since there contains various unknown

319 organic matters as listed in Table $1(\mathrm{COD}=358 \mathrm{mg} / \mathrm{L})$. However, since the synthetic

320 brine contains no other chemicals except the inorganic salt, the tendency for the

321 membrane to be fouled by other matters besides inorganic salt is low. Moreover, the

322 synthetic brine contains mainly ions in chloride from, the solubility is relatively high,

323 thus no scaling was observed at a concentration factor of 2 . When comparing the

324 membrane surfaces of CTA membranes, it is indeed quite a surprise that the

325 membrane surface relatively clean and no obvious fouling was observed, which was

326 supported by the overlapping FO flux curves for both synthetic brine and SGDF as

327 shown in Fig. 2 and 3.

328 The complex nature of the real SGDF resulted in a quick formation of fouling 329 layer on TFC membrane surface. After formation of the fouling layer (as seen in Fig. 330 4), no severe mass transfer resistance was observed. CTA membrane showed the same 
331 flux when treating SGDF as treating clean synthetic water. By combining the above 332 observation, it may be safe to conclude that the TFC membrane is prone to fouling by 333 the contaminants in SGDF, although the initial FO flux was not the same.
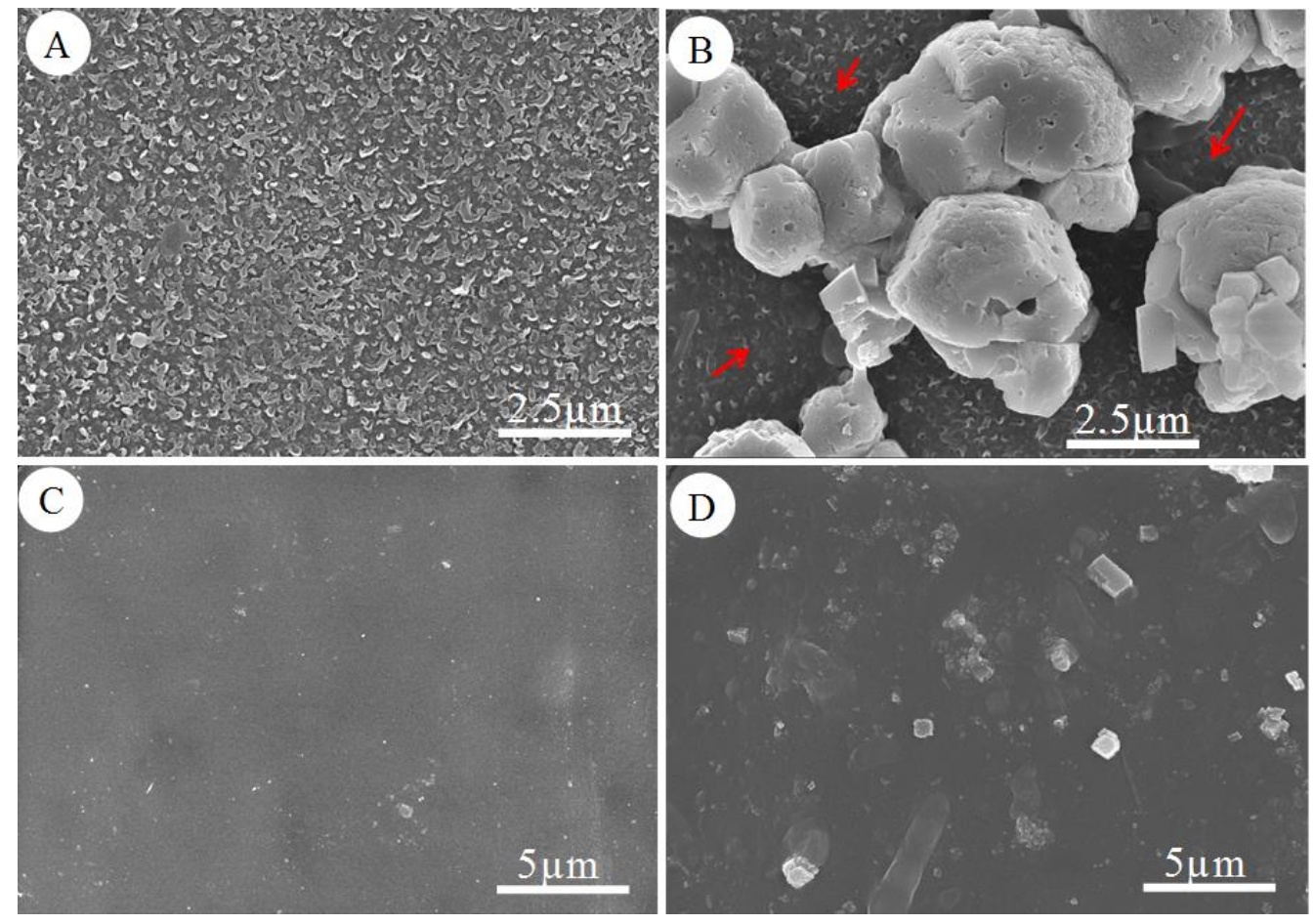

Figure 4. SEM photos of the top surfaces of the TFC membranes, (A) after

337 treating synthetic brine; (B) after treating SGDF; and top surfaces of the CTA

338 membranes, (C) treating synthetic brine; (D) after treating SGDF. The arrows refer to

339 surface area appeared to be covered by foulants. 

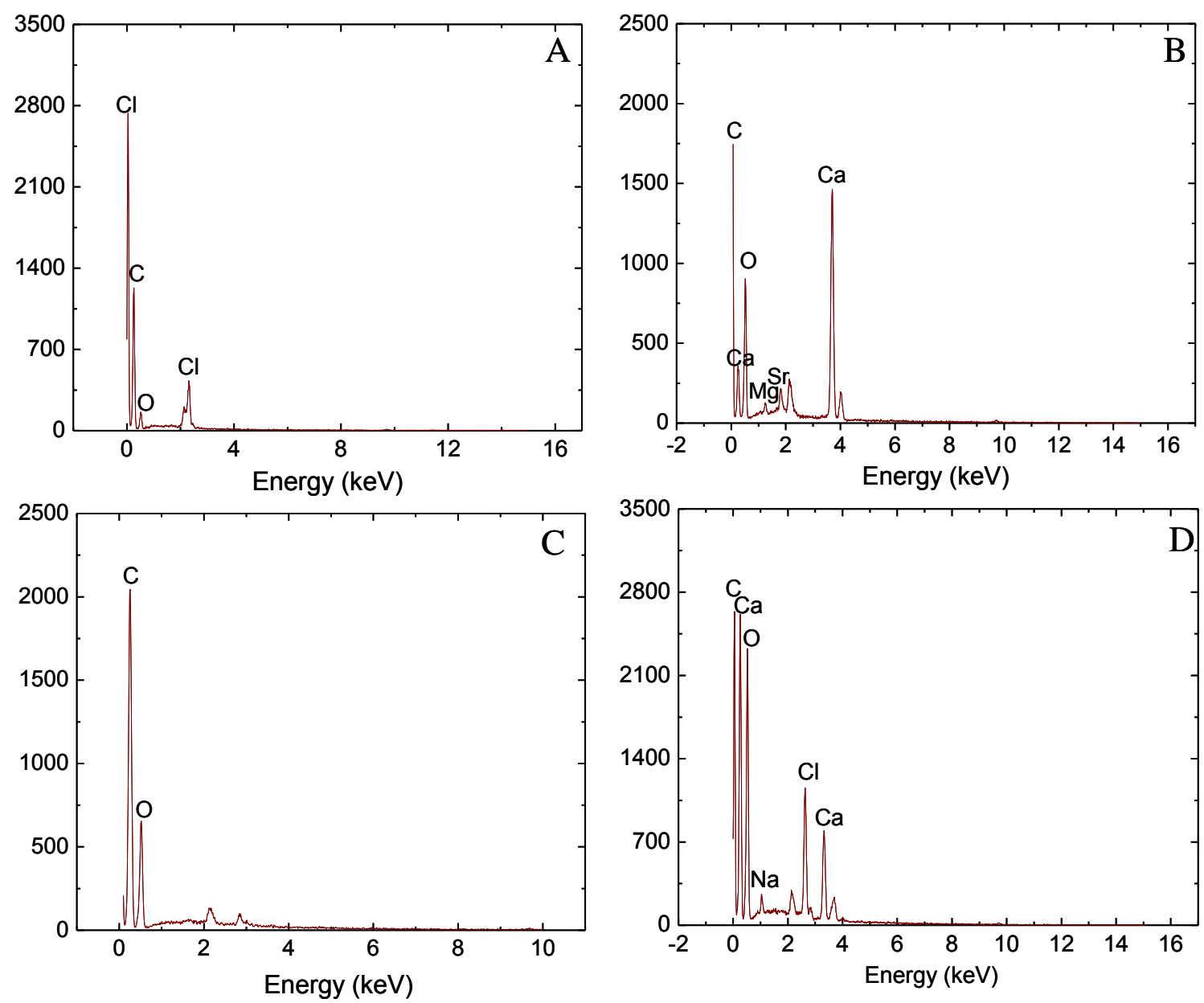

Figure 5 EDS analysis of the top surfaces of flat sheet TFC membranes (A, fresh

344 and B, after concentrating SGDF) and CTA membranes (C fresh; and D after

345 concentrating SGDF)

\subsection{Fouling mechanism}

The results presented above indicate that TFC membrane is prone to fouling when

349 exposed to the real SGDF. Taking the membrane surface morphology into account as

350 shown in Fig. 1, it appears that the difference in membrane surface morphology is a

351 major reason for the high fouling propensity of the TFC compared to the CTA

352 membrane. The FO flux of TFC membrane (Fig.2 and Fig. 3) treating SGDF declined 
353 almost instantaneously to about $75 \%$ at the beginning of the experiment. Combining 354 this and the SEM photo (Fig. 4 B), the quick fouling may be due to the filling-up of 355 the ridge-and-valley surface by foulants in the real SGDF (Fig 6). On the other hand, 356 the smooth surface of the CTA membrane reduces foulant deposition. Thus the 357 membrane surface was as clean as pristine membrane.

358 As schematically described in Fig. 6B, once the TFC surface is filled up, no 359 additional aggregation of foulants can occur and the fouled membrane surface is now 360 smooth. The duration of fouling buildup is obviously very quick, as shown in Fig. 2 361 and Fig. 3. This may be caused by the large amount of foulants (including organic 362 matter and colloidal particles) in the real SGDF $[13,21]$. The SGDF contains a wide 363 distribution of particles with a maximum distribution intensity at $\sim 1.2 \mu \mathrm{m}$ 364 (Supplementary Information Fig. S1). Even after pre-filtration with a commercial 365 ultrafiltration membrane of molecular weight cutoff of about $70000 \mathrm{Da}$., there remain 366 some particles of with a mean size of $0.3 \mu \mathrm{m}$. Therefore, formation of a severe fouling 367 on the FO membrane is highly possible. By pre-filtrating the SGDF, the initial fouling 368 of the TFC membrane was slowed down (Supplementary Data Fig. S2). This was 369 probably due to the lower foulant content after ultrafiltration. However, the FO flux 370 declined gradually to a similar pattern as shown in Fig. 2 (B). 

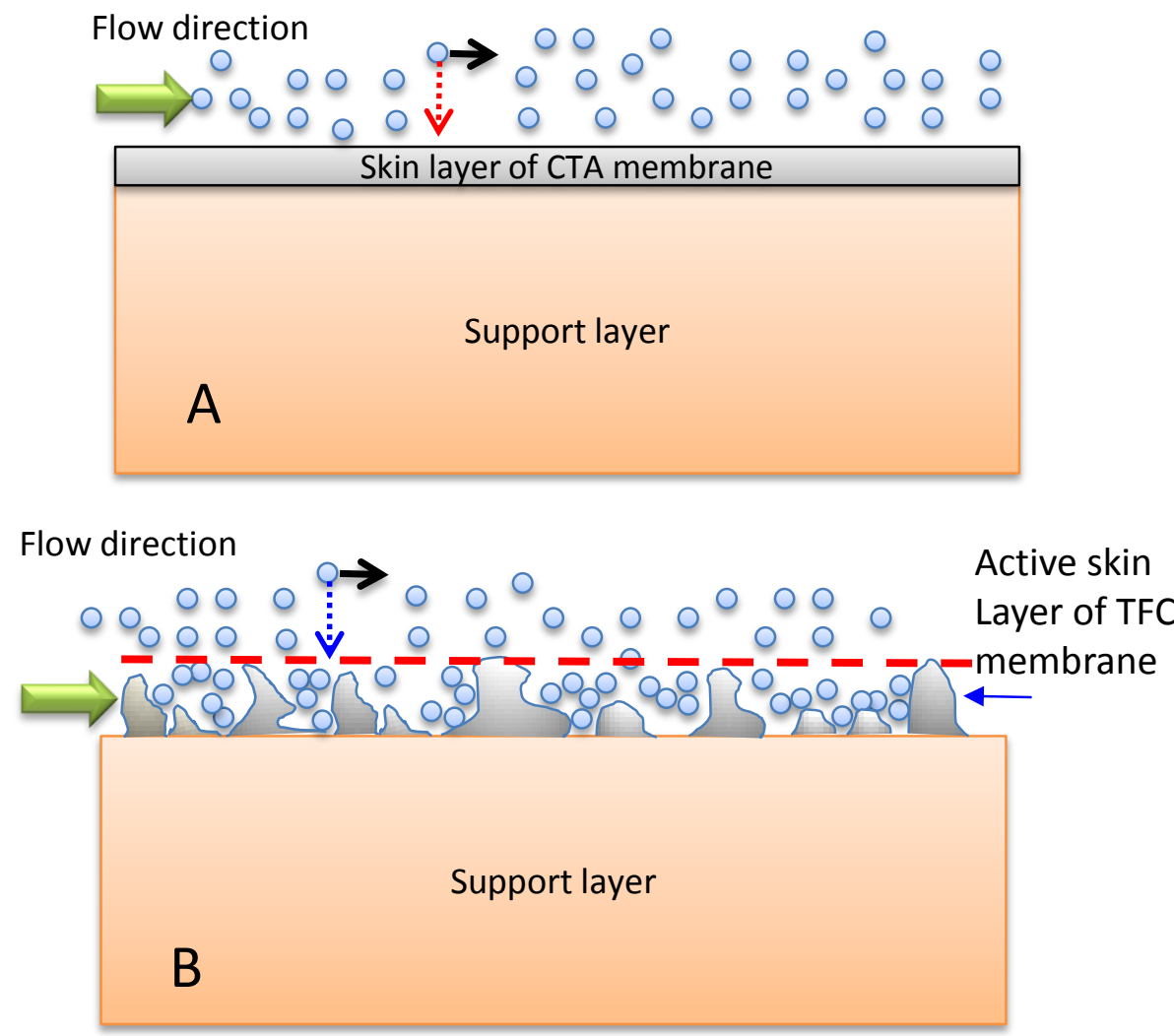

Fig. 6 Schematic of the fouling mechanism during the FO treatment of SGDF.

375 The small spheres represent possible foulants in the SGDF which may aggregate to

376 the surface. The dashed line indicates the top boundary between the active skin layer 377 and the feed bulk solution.

\subsection{PEG grafting}

380 Above investigation on the fouling formation during FO of SGDF shows that TFC

381 membrane tends to be fouled easier than CTA membrane. Results also indicated that

382 initial aggregation of the foulants to the rough surface was the starting point.

383 Reducing the content of foulant matter only delayed the membrane fouling. Therefore,

384 in this session, PEG grafting of the TFC membrane surface was adopted to reduce the

385 fouling propensity [13]. The PEG layer can reduce the TFC membrane surface 
roughness and adhesion force between the surface and foulants, which has been

387 ascribed as the main reason for fouling reduction for TFC FO membrane after

388 PEGylation [13]. Jeffamine was used as the PEGylation agent. No significant changes

389 in the surface of the Jeffamine modified TFC membrane were observed (Fig.7A).

390 However, as can be seen in Fig. 7B the surface contact angle of modified membrane

391 decreased significantly from $86 \pm 2.3^{\circ}$ (unmodified membrane) to $34 \pm 1.5^{\circ}$

392 (PEGylated membrane). This is in agreement with previous results in the literature

393 [13], confirming that the PEGylation has been successful.

a
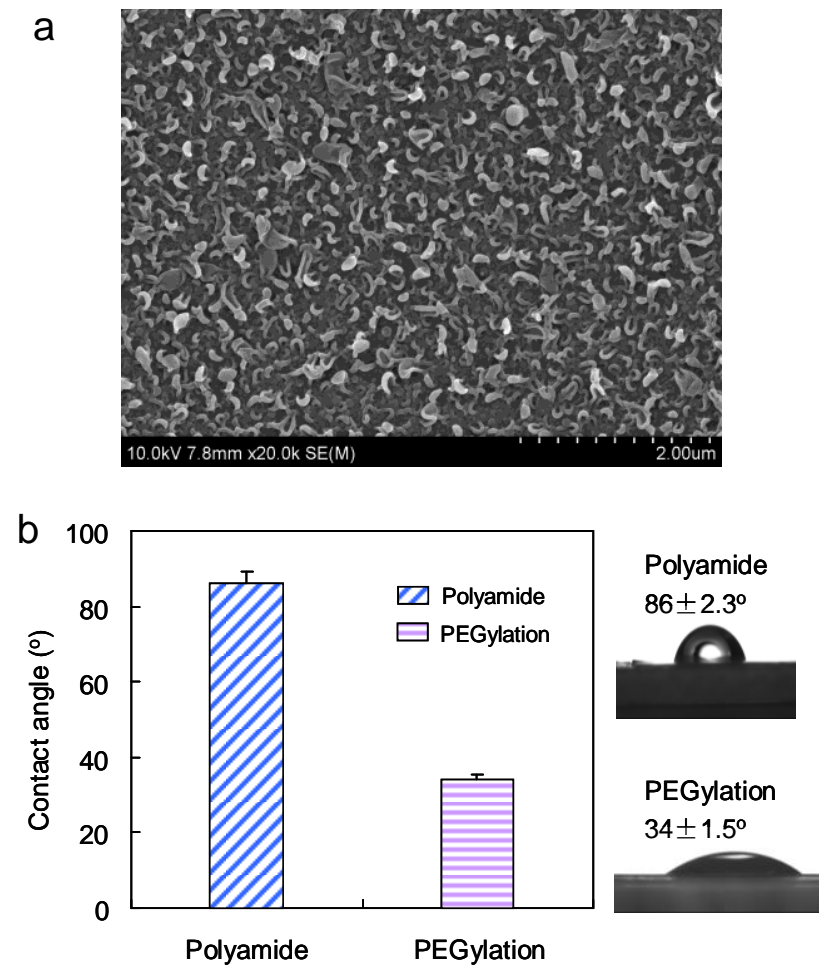

396 Fig. 7. (A) An SEM image of the PEGylated TFC membrane surface and (B) contact angles of TFC membrane before and after PEGylation.

Again, the water flux ratio, $\mathrm{J}_{\mathrm{SG}} / \mathrm{J}_{\mathrm{SB}}$, was monitored for the TFC membranes after 
PEGylation. After PEGylation, the water flux ratio stayed nearly constantly above

$40190 \%$, in contrast to $\pm 75 \%$ before PEGylation, as shown in Fig. 8. Results confirmed 402 that PEGylation improves significantly the water flux of the TFC membrane. It should 403 be noted that that PEGylation resulted in reduction in the water flux value of about $40420 \%$. However, TFC membrane surface grafted with PEG has reduced adhesion to the 405 foulants, resulting in a fouling-resistance membrane. Similar observations have been 406 also reported previously [22-25]. SEM images of the PEGylated TFC membranes 407 after SGDF treatment are shown Supplementary Information Fig. S3. Slight coverage 408 of the surface by potential foulant was visible, however, no obvious scaling was found. 409 This observation confirmed the FO performance as shown in Fig. 8. However, the FO 410 flux indicates that the resistance of the fouling layer was not as significant as that 411 formed on the unmodified TFC membrane (Fig. 3). The results confirm that the 412 PEGylation is a very efficient way to reduce the membrane fouling. Further 413 optimization of the grafting density and layer thickness is necessary to maintain 414 optimal FO performance. 


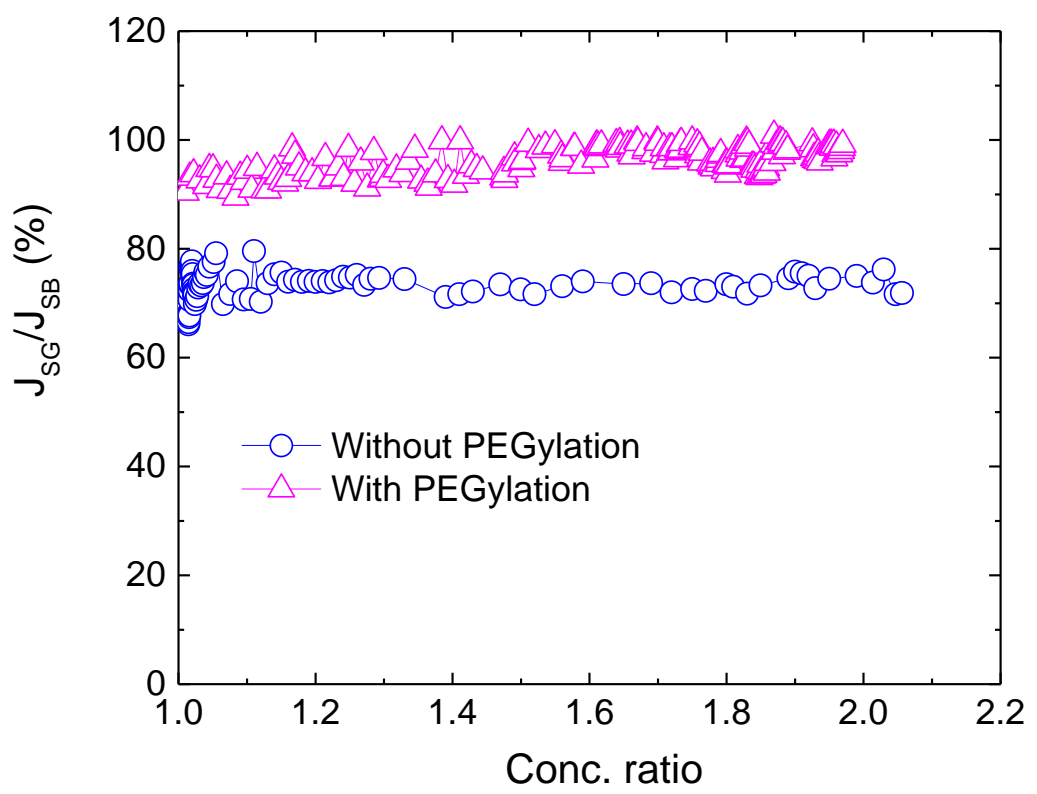

417 Fig. 8 Water flux ratio $\left(\mathrm{J}_{\mathrm{SG}} / \mathrm{J}_{\mathrm{SB}}\right)$ against the concentration ratio of the feed streams

418 using PEGylated TFC membranes. (Synthetic brine and real SGDF were used as feed

419 solutions, respectively. $3 \mathrm{M} \mathrm{KCl}$ was used as draw solution. Experiments were carried 420 out in the FO mode at a flow velocity of $4.6 \mathrm{~cm} / \mathrm{s}$. The temperature is maintained at 30 $\left.421 \pm 0.5^{\circ} \mathrm{C}\right)$

\section{Conclusions}

A polyamide on polysulfone support TFC membrane was fabricated and used for concentrating shale gas drilling flow back fluid (SGDF). The compositions of SGDF and membrane surface morphology were studied for their effects on flux patterns. It

427 was shown that the CTA membrane exhibits a low water flux but is highly fouling 428 resistant. The presence of submicron-sized colloidal particles did not affect the water 429 flux of the CTA membrane. On the other hand, the polyamide TFC membrane shows a 430 high water flux when treating synthetic brine but is prone to membrane fouling when 
431 treating real SGDF. The high fouling propensity of the polyamide TFC membrane

432 fabricated in this study could be ascribed to its rough and hydrophobic membrane

433 surface as well as the presence of colloidal particles in the real SGDF. Our study also

434 demonstrates that surface PEGylation of the TFC membranes could significantly

435 improve its fouling resistance while the reduction in pure water flux (due to

436 PEGylation) was only marginal.

437

\section{Acknowledgements}

439 The authors would like to thank the partial financial support from National

440 Natural Science Fund China (Project nos. 21176119), Shell Frontier Research

441 Funding (Project No. PT31966), the National Key Basic Research Program of China

442 (973 Program with project nos. 2012CB932800). 
A

B

$C_{f}$

$C_{p}$

$J_{v}$

$J_{w}$

$J_{s}$

K

$k$

$D$

$L$

$\Pi$

$\varepsilon$

$P$

S

E

$\tau$

$t_{s} \quad$ thickness $(\mu \mathrm{m})$

$m_{1} \quad$ wet membrane weight $(\mathrm{g})$

$m_{2} \quad$ dry membrane weight $(\mathrm{g})$

M mass of permeate water $(\mathrm{g})$ 


$\begin{array}{ll}\rho_{w} & \text { water density }\left(\mathrm{g} / \mathrm{cm}^{3}\right) \\ \rho_{p} & \text { polymer density }\left(\mathrm{g} / \mathrm{cm}^{3}\right) \\ S h & \text { Sherwood number } \\ R e & \text { Reynolds number } \\ S c & \text { Schmidt number } \\ \Delta t & \text { measured time (s) } \\ \Delta m & \text { effective membrane area }\left(\mathrm{cm}^{2}\right) \\ S_{m} & \text { the number of dissolved species of draw solution } \\ N & \left.\text { ideal gas constant (L.atm.mol } \mathrm{mol}^{-1} \cdot \mathrm{K}^{-1}\right) \\ R & \text { absolute temperature }(\mathrm{K}) \\ T & \end{array}$

444 


\section{References}

[1] B.G. Rahm, J.T. Bates, L.R. Bertoia, A.E. Galford, D.A. Yoxtheimer, S.J. Riha, Wastewater management and Marcellus Shale gas development: Trends, drivers, and planning implications, Journal of Environmental Management, 120 (2013) 105-113.

[2] K.L. Hickenbottom, N.T. Hancock, N.R. Hutchings, E.W. Appleton, E.G. Beaudry, P. Xu, T.Y. Cath, Forward osmosis treatment of drilling mud and fracturing wastewater from oil and gas operations, Desalination, 312 (2013) 60-66.

[3] B.G. Rahm, S.J. Riha, Toward strategic management of shale gas development: Regional, collective impacts on water resources, Environmental Science \& Policy, 17 (2012) 12-23.

[4] L. Shariq, Uncertainties associated with the reuse of treated hydraulic fracturing wastewater for crop irrigation, Environmental Science \& Technology, 47 (2013) 2435-2436.

[5] T.Y. Cath, A.E. Childress, M. Elimelech, Forward osmosis: Principles, applications, and recent developments, Journal of Membrane Science, 281 (2006) 70-87.

[6] S. Zhao, L. Zou, C.Y. Tang, D. Mulcahy, Recent developments in forward osmosis: Opportunities and challenges, Journal of Membrane Science, 396 (2012) 1-21.

[7] D.L. Shaffer, L.H.A. Chavez, M. Ben-Sasson, S.R.-V. Castrillon, N.Y. Yip, M. Elimelech, Desalination and Reuse of High-Salinity Shale Gas Produced Water: Drivers, Technologies, and Future Directions, Environmental Science \& Technology, 47 (2013) 9569-9583.

[8] T.-S. Chung, X. Li, R.C. Ong, Q. Ge, H. Wang, G. Han, Emerging forward osmosis (FO) technologies and challenges ahead for clean water and clean energy applications, Current Opinion in Chemical Engineering, 1 (2012) 246-257.

[9] L.A. Hoover, W.A. Phillip, A. Tiraferri, N.Y. Yip, M. Elimelech, Forward osmosis: emerging applications for greater sustainability, Environmental Science \& Technology, 45 (2011) 9824-9830.

[10] R.L. McGinnis, N.T. Hancock, M.S. Nowosielski-Slepowron, G.D. McGurgan, Pilot demonstration of the $\mathrm{NH} 3 / \mathrm{CO} 2$ forward osmosis desalination process on high salinity brines, Desalination, 312 (2013) 67-74.

[11] HTI, Oil wastewater treatment \& gas treatment: lead story, in, 2011.

[12] X.M. Li, B.L. Zhao, Z.W. Wang, M. Xie, J.F. Song, L.D. Nghiem, T. He, Y. Chi, C.X. Li, G. Chen, Water reclamation from shale gas drilling flow-back fluid using a novel forward osmosis-vacuum membrane distillation hybrid system, Water Science and Technology, 69 (2014) 1036-1044.

[13] X.L. Lu, S.R.-V. Castrillon, D.L. Shaffer, J. Ma, M. Elimelech, In situ surface chemical modification of thin-film composite forward osmosis membranes for enhanced organic fouling resistance, Environmental Science \& Technology, 47 (2013) 12219-12228.

[14] T.Y. Cath, M. Elimelech, J.R. McCutcheon, R.L. McGinnis, A. Achilli, D. Anastasio, A.R. Brady, A.E. Childress, I.V. Farr, N.T. Hancock, J. Lampi, L.D. Nghiem, M. Xie, N.Y. Yip, Standard Methodology for Evaluating Membrane Performance in Osmotically Driven Membrane Processes, Desalination, 312 (2013) 31-38.

[15] W.A. Phillip, J.S. Yong, M. Elimelech, Reverse draw solute permeation in forward osmosis: modeling and experiments, Environmental Science \& Technology, 44 (2010) 5170-5176.

[16] C.Y. Tang, Q. She, W.C.L. Lay, R. Wang, A.G. Fane, Coupled effects of internal concentration polarization and fouling on flux behavior of forward osmosis membranes during humic acid filtration, Journal of Membrane Science, 354 (2010) 123-133.

[17] X. Jin, C.Y. Tang, Y.S. Gu, Q.H. She, S. Qi, Boric acid permeation in forward osmosis membrane 
process: modeling, experiments, and implications, Environmental Science \& Technology, 45 (2011) 2323-2330.

[18] E.M.V. Hoek, A.S. Kim, M. Elimelech, Influence of crossflow membrane filter geometry and shear rate on colloidal fouling in reverse osmosis and nanofiltration separations, Environmental Engineering \& Science, 19 (2002) 357-372.

[19] S. Loeb, L. Titelman, E. Korngold, J. Freiman, Effect of porous support fabric on osmosis through a Loeb-Sourirajan type asymmetric membrane, Journal of Membrane Science, 129 (1997) 243-249.

[20] J.R. McCutcheon, M. Elimelech, Influence of membrane support layer hydrophobicity on water flux in osmotically driven membrane processes, Journal of Membrane Science, 318 (2008) 458-466.

[21] X.-M. Li, B. Zhao, Z. Wang, M. Xie, J. Song, L.D. Nghiem, T. He, C. Yang, C. Li, G. Chen, Water reclamation from shale gas drilling flow-back fluid using a novel forward osmosis-vacuum membrane distillation hybrid system, Water Science Technology, 69 (2014) 1036-1044.

[22] A.C. Sagle, E.M. Van Wagner, H. Ju, B.D. McCloskey, B.D. Freeman, M.M. Sharma, PEG-coated reverse osmosis membranes: Desalination properties and fouling resistance, Journal of Membrane Science, 340 (2009) 92-108.

[23] F. Li, J. Meng, J. Ye, B. Yang, Q. Tian, C. Deng, Surface modification of PES ultrafiltration membrane by polydopamine coating and poly(ethylene glycol) grafting: Morphology, stability, and anti-fouling, Desalination, 344 (2014) 422-430.

[24] S. Romero-Vargas Castrillón, X. Lu, D.L. Shaffer, M. Elimelech, Amine enrichment and poly(ethylene glycol) (PEG) surface modification of thin-film composite forward osmosis membranes for organic fouling control, Journal of Membrane Science, 450 (2014) 331-339.

[25] M.Z. Yunos, Z. Harun, H. Basri, A.F. Ismail, Studies on fouling by natural organic matter (NOM) on polysulfone membranes: Effect of polyethylene glycol (PEG), Desalination, 333 (2014) 36-44. 